\title{
Age and Sex-Related Geometrical Variation of Ramus mandibulae of Sus scrofa's (Mammalia: Artiodactyla) Jaws
}

\author{
Variaciones Geométricas del Ramus mandibulae en Mandíbulas de \\ Sus scrofa (Mammalia: Artiodactyla) según Edad y Sexo
}

Leandro dos S. L. Hohl*; Fernando L. Sicuro**; Concepción Azorit"**; Rafael Carrasco*** \& Oscar Rocha-Barbosa*

HOHL, L. S. L.; SICURO, F. L.; AZORIT, C.; CARRASCO, R. \& ROCHA-BARBOSA, O. Age and sex-related geometrical variation of Ramus mandibulae of Sus scrofa's (Mammalia: Artiodactyla) jaws. Int. J. Morphol., 32(4):1282-1288, 2014.

SUMMARY: Morphological variation of the ramus mandibulae of wild Sus scrofa was described and correlated to sex and age differences. Young forms ( $\mathrm{n}=27,15$ males, 12 females) and adults ( $\mathrm{n}=23,13$ males, 10 females) were analyzed through Geometric Morphometrics (2-D) to assess differences between groups. We found significant differences between age- and sex-related shape variations at ramus mandibulae level. Young wild boars present bulky angular process with backward oriented coronoid process, while adults show slender jaw vertical ramus, and orthogonally oriented coronoid process. The ramus mandibulae in female wild boars is more robust and bulky than in males. The morphological changes between young and adult forms are related to alterations in the osteo-muscular jaw complex along wild boars ontogeny. The jaw morphological variations observed in adult wild boars could also be related to dietary differences between sexes.

KEY WORDS: Mandible; Ontogeny; Sexual Dimorphism; Wild boar.

\section{INTRODUCTION}

Wild boars (Sus scrofa, Linnaeus 1758) present one of the widest distributions among ungulates, including the original populations in Eurasia and also in other continents where they were introduced (Groves \& Grubb, 1993). Wild boars and humans share a long term ecological and cultural past as, boars provided a source of game meat and their jaw fangs were a coveted prize (Fonseca \& Correia, 2008).

External body sexual dimorphism is evident among adult wild boars especially concerning the skull. The condylobasal length of adult females is $88.8 \%-95.3 \%$ that of adult males (Groves \& Grubb, 1993; Moretti, 1995; Genov et al., 1995) and the male upper canines curve upwards. The powerful lower canines are well developed and are curved backwards (Fig. 1), being constantly sharpened by the upper canines. Notwithstanding, few studies of sexual dimorphism on cranial morphology using qualitative descriptions and morphometric approaches exist
(Groves \& Grubb; Genov et al.; Moretti). Cucchi et al. (2011) tried to detect sexual and age specific morphological differences among wild boars through a geometric morphometric analysis of cranial features. Despite their efforts, these authors failed to demonstrate the validity of the $\mathrm{M}_{2}$ as a basis to support their hypothesis. Hitherto, the age-class determination of wild boars still relies on dental formula, tooth eruption (Sáez-Royuela et al., 1989), and external body characteristics such as pelage variation (Fonseca \& Correia). Sex and age classification is usually based on observations of whole skull anatomy and/or complete body with all its external features, though sexual dimorphism is not evident in juveniles until 18 to 19 months of age (Pedone et al., 1995). The dental formula of adults is $\mathrm{i} 3 / 3, \mathrm{c} 1 / 1, \mathrm{p} 4 / 4$ and $\mathrm{m} 3 / 3$ while sub-adults are characterized by I 3/3, C 1/1, P 4/4, M 2/3 (molar three lower in eruption stage), only the total eruption of the lower third molar characterizes adult animals (Sáez-Royuela et al.).

LAZOVERTE - Laboratório de Zoologia de Vertebrados - Tetrapoda, Departamento de Zoologia, IBRAG, Universidade do Estado do Rio de Janeiro, Rio de Janeiro, Brazil.

** BIOVASC - Departamento de Ciências Fisiológicas, IBRAG, Universidade do Estado do Rio de Janeiro - UERJ, Rio de Janeiro, Brazil.

**** Department of Animal and Vegetal Biology and Ecology, Faculty of Experimental Sciences, University of Jaén, Jaén, Spain.

Financial support: European Fund For Regional Development (FEDER); Consejería de Ciencia e Innovación de la Junta de Andalucía (P07-RNM03087); Ministerio de Educación y Ciencia (CGL-2008-00832); Programa Intercambio y Movilidad Académica PIMA of OEI; Prociência ProgramUERJ, FAPERJ (E-26/101.070/2013); Brazilian National Counsel of Technological and Scientific Development - CNPq (312942/2009-5). 


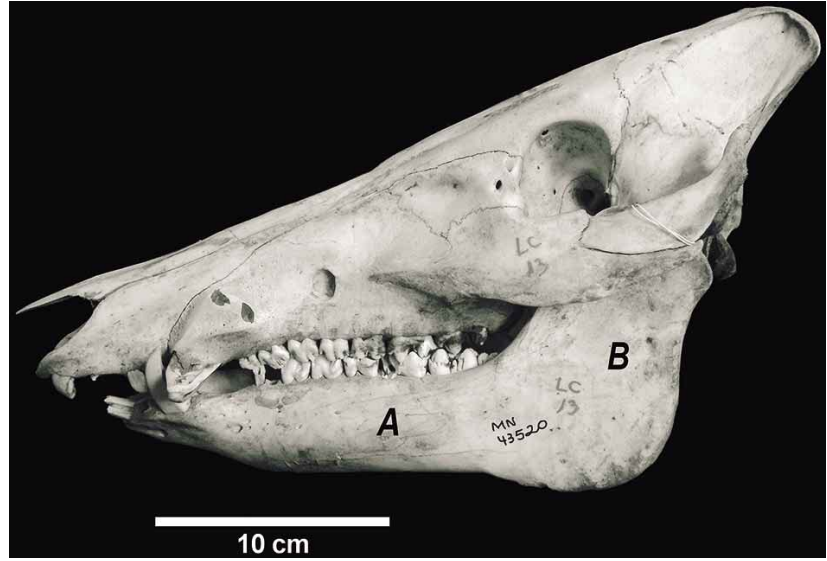

Fig. 1. Adult male wild boar's skull and jaw presenting the corpus (A) and ramus mandibulae (B). Specimen MN43520.

Morphological variation in the jaw of S. scrofa has been studied regarding geographic distribution, sex, ontogeny, and temporal dissimilarities between extinct and extant specimens using classical and geometric morphometric approaches (Endo et al., 2002; Cucchi et al.).

The ramus mandibulae corresponds to the perpendicular portion of the mammalian jaw connected to the posterior part of the corpus mandibulae (Standring, 2008). It has a quadrilateral shape and presents three processes: the condyloid, coronoid and angular (which correspond to the in-lever arms of the jaw muscles). The three main muscle groups related to jaw occlusion that are attached to the ramus are the following: Masseter/Mandibular Zigomatic, Temporal, and Pterygoid (Turnbull, 1970). Thus, the ramus mandibulae plays important morphofunctional and ecomorphological roles due to the correlation between jaw shape and feeding strategies (Pérez-Barbería \& Gordon, 1999).

Geometric Morphometrics is concerned with the study of variation and covariation of shape and size among organisms through a configuration of anatomical homologous landmarks on a Cartesian coordinates grid (Bookstein, 1997). Semi-landmarks represent a series of points to approximate a curve or a surface in the absence of well defined landmarks (Bookstein). The semi-landmarks method assumes a more flexible and classical concept than homology of points; this method uses the notion of homologous corresponding parts, geometrically defined by curves or surfaces (Gunz et al., 2005). Bookstein suggested the sliding semi-landmarks approach as a way to deal with landmarks and semi-landmarks as equivalents, despite the lack of biological homology of the latter.

In the present study we described the age and sex morphological variation of wild boars through their ramus mandibulae (usually discarded by hunters). Based on the geometric alterations of the ramus mandibulae among young and adult wild boars of the both sexes, we raised some hypotheses about the correlation of this feature and biological and ecological scenarios.

\section{MATERIAL AND METHOD}

We analyzed te mandibles from 50 wild boar's a sample that includes juveniles ( $n=22,11$ males, 11 females) subadults $(n=5,4$ males, 1 female) adults $(n=23,13$ males, 10 females). These specimens of European wild boars are deposited at the Universidad de Jaén, Andalucía, Spain; and Museu Nacional, Universidade Federal do Rio de Janeiro, Brazil (Fig. 2). Age of specimens was determined from information recorded in the collections or through age classification by Sáez-Royuela et al. Therefore, based on teeth eruption, the sample is composed by young (i.e. juveniles, less than 21-months-old, and sub-adults aged 21-26-months) and adult forms ( $\geq 26$-months-old).

Images of the outer side of the left dental bone were acquired through a digital camera (Canon EOS 550D, 18.0 Mpx, 3x optic zoom, EF-S IS 18-55 mm lens) fixed at standard height $(55 \mathrm{~cm})$, and with the same settings (magnification, depth of field, white balance).

The morphological analysis were performed using a Procrustes based Morphometric approach (Viscosi \& Cardini, 2013). We marked four Type II landmarks and eight semi-landmarks to describe the ramus mandibulae outline (Table I) by using the software TPSDig2 version 2.05 (Rohlf,

Table I. Semi-landmarks and landmarks descriptions.

1 - Coronoid process extremity

2 - Maximum curvature point of mandibular notch

3 - Articular head extremity of condylar process

4 - Narrow condylar process extremity

$5,6,7,8$ and 9 - Jaw's branch posterior margin, covering the mandibular angle and facial vessels notch

10,11 and 12 - Jaw's branch anterior margin, covering the mandibular angle 
2004). The eight semi-landmarks were positioned on the intersection formed by the edges of the ramus mandibulae and 24 isoangular lines (Fig. 3) generated by MakeFan6 software (Sheets, 2011). Procrustes least-squares superimposition was performed on CoordGen6p (Sheets) in order to remove the effects of size, position and orientation of coordinates (Bookstein). The software Semiland6 was then used to semi-landmark sliding procedure. Data were analyzed through Canonical Variate Analysis (CVA) using the sliding procrusted coordinates of the original groups of wild boars (young males, young females, adult males, and adult females) as the a priori classification. Individuals were separated in groups according to sex (male and female) and age classes. The option forward stepwise was used in order

\begin{tabular}{|c|}
\hline 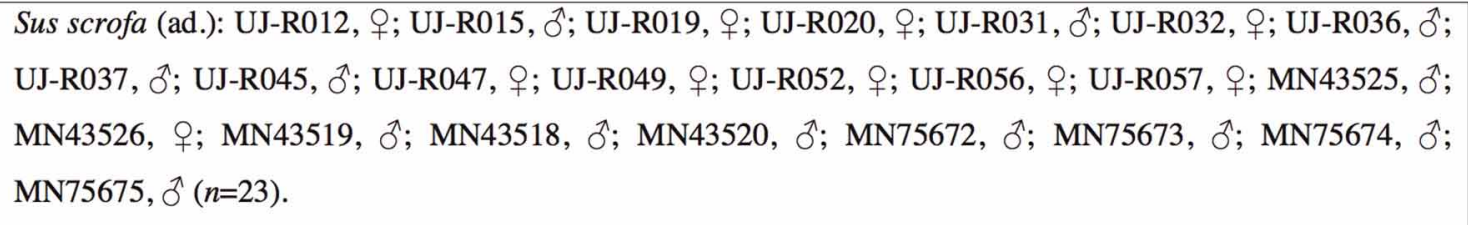 \\
\hline 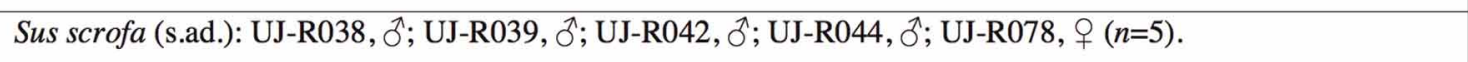 \\
\hline 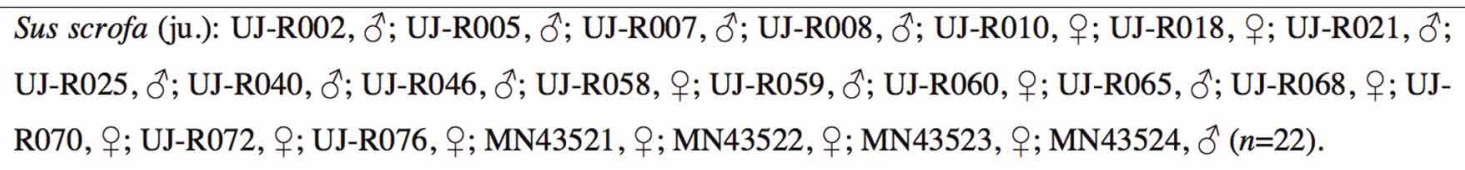 \\
\hline
\end{tabular}

Fig. 2. List of measured specimens by collection. UJ-R: Universidad de Jaén, Andaluzía, Spain; MN: Museu Nacional, Universidade Federal do Rio de Janeiro, RJ, Brazil.

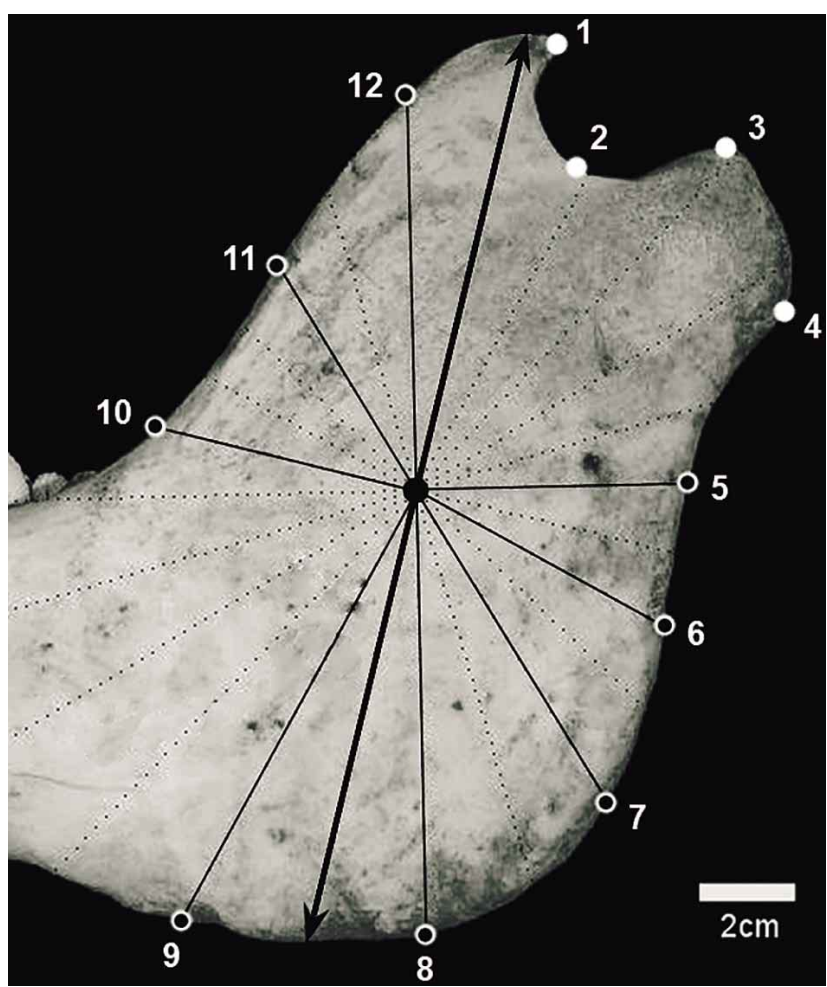

Fig. 3. Positioning of landmarks and semi-landmarks at the edges of the fan bold lines. The height of jaw used as reference to make "fan" is represented by full line with arrows on extremities. Landmarks 1-4 are represented by full circles and semi-landmarks 5-12 by empty circles. Dashed-lines were not used to generate semi-landmarks. to keep the variables with more relevance to the group discrimination. The Squared Mahalanobis Distance was used as a post-hoc significance test when the Wilks' Lambda indicated significant difference between morphological spaces in CVA. The centroid size values were used as size comparisons between age- and sex-groups through KruskalWallis non-parametric ANOVA.

\section{RESULTS}

The univariate comparison using the centroid sizes indicated the size superiority of the ramus mandibulae of adult male wild boars when compared to young males (Kruskal-Wallis $\mathrm{H}_{3},{ }_{50}=19.32, P<0.001$; Dunn's test, $P=0.001$ ), and young females (Kruskal-Wallis $\mathrm{H}_{3},{ }_{50}=19.32$, $P<0.001$; Dunn's test, $P=0.001)$. There are no differences between adult females and young forms of both sexes, suggesting the observed variations found are not size related.

The CVA analysis produced two main roots of group differentiation (Fig. 4): CV1 explained $57.6 \%$ of shape variation, CV2 explained $38.5 \%$ of variation, and the overall variation explained by the CVA analysis was $96.1 \%$. There are significant differences between groups (Wilks' Lambda $\left.=0.07965 ; \mathrm{F}_{33},{ }_{106}=4.4010, P<0.0001\right)$. Square Mahalanobis Distances indicated significant separation between the morphological spaces of young and adult male wild boars 
Table II. Square Mahalanobis Distances analysis as post hoc significance test between the morphological spaces of each group.

\begin{tabular}{lcc}
\hline Groups & $\boldsymbol{F}_{\mathbf{1 1}, \mathbf{3 6}}$ & $\boldsymbol{P}$ \\
\hline Young/adult (Male) & 2.96 & $<0.01$ \\
Young/adult (Female) & 6.82 & $<0.00001$ \\
Adult (Male - Female) & 4.50 & $<0.001$ \\
Young (Male - Female) & 2.87 & $<0.01$ \\
\hline
\end{tabular}

Canonical Variate Analysis: Wilks' $1=0.07965 ;$ F33, $106=4.4010$ $\mathrm{P}<0.00001$

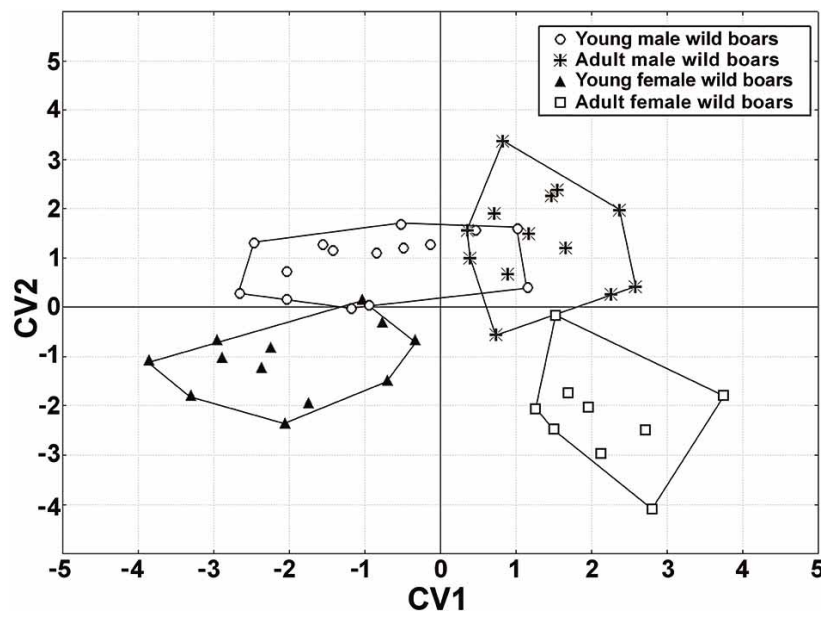

Fig. 4. Canonical Variate Analysis scatterplot. CV1 represents the age variation and $\mathrm{CV} 2$ represents the sexual variation between both adult and juvenile wild boars. The first canonical variable explains $57.6 \%$ of sample variation and the second canonical variable explains $38.5 \%$ of sample variation. The specimen R056 was considered an outlier and removed from scatterplot.

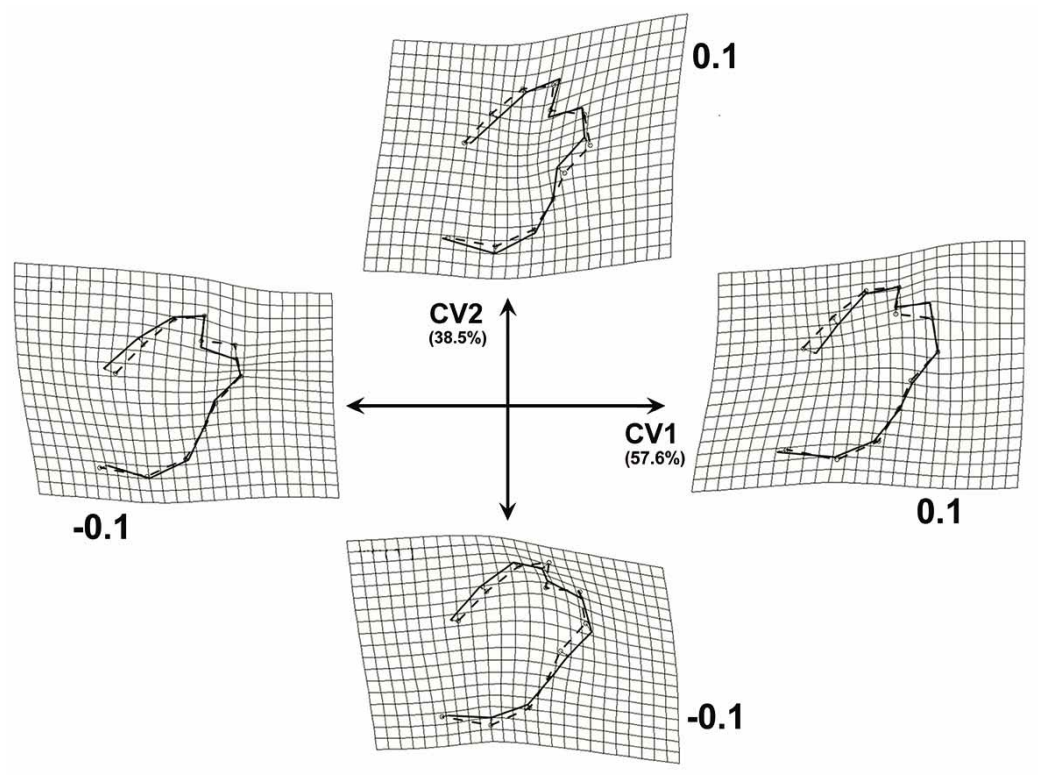

Fig. 5. Thin-plate spline deformation grids in relation to reference shape along CV1 and CV2 axis. The deformation is represented by full line and reference shape by dashed-lines.
$\left(\mathrm{F}_{11},{ }_{36}=2.96, P<0.01\right)$ and young and adult female wild boars $\left(\mathrm{F}_{11}{ }_{36}=6.82, P<0.0001\right)$ on $\mathrm{CV} 1$ axis (Table II). Thus, this root could be labeled as age variation where the size allometry seems to play little role in the difference between groups. On the other hand, the Square Mahalanobis Distance among groups in the CV2 indicated significant differences between sexes in adult wild boars $\left(\mathrm{F}_{11},{ }_{36}=4.50, P<0.001\right)$, as well as, in the young wild boars $\left(\mathrm{FF}_{11},{ }_{36}=2.87, P<0.01\right)$. Thus, this root could be labeled as sexual dimorphism present in the both adult and juvenile wild boars.

Morphological variation along CV1. Young S. scrofa spread in the negative side of the CV1 axis. The anterior margin of the ramus mandibulae is forwardly projected, while the posterior margin seems backwardly projected. Thus, the mandibular branch of the young wild boars has a rounded and robust shape in relation to the consensus figure (Fig. 5). Coronoid process apex is orthogonally oriented. Condylar process head is marked downwardly positioned almost meeting the narrow condylar process. Due to this fact, the condylar process presents a backward pointed aspect. Adult wild boars' scores are observed the positive side of the CV1 axis. Their ramus mandibulae presents their anterior part as elongated and slender. The angular process is slightly curved with its connection to the condylar process almost rectified. Coronoid process apex is more backwardly oriented than found in young forms. Adult wild boars also exhibit a robust condylar process.

Thus, age-related variation in the ramus mandibulae of wild boars could be summarized as young forms featuring a bulky ramus with pointed condylar process, while in the adult ones this trait is slender with powerful condylar process.

Morphological variation along CV2. All male forms of $S$. scrofa spread over the positive side of the CV2 axis (Fig. 5). The coronoid and condylar process are slender while the angular process has a curved robust shape. The anterior part of the ramus mandibulae is elongated and slender. The coronoid process apex is pronounced upand backwardly oriented, giving the coronoid process a thin and elongated aspect. The condylar process seems to be elevated as a whole. The general aspect of the condylar process in male wild boars' is elongated and slender. Wild boar females are mainly spread over the negative part of the CV2 axis. The shape of the mandibular branch is rounded and robust. 
The anterior margin of this structure is marked convex. The inferior part of the angular process shows a discrete curvature and its connection to condylar process is almost rectified. The coronoid process is short and wide. The condylar process seems broad and robust.

Therefore, sex-related variation in the ramus mandibulae of wild boars' could be summarized as females featuring an overall bulky ramus, while males present this trait as being much more slender, but with an elongated upwardly oriented condylar process.

\section{DISCUSSION}

We found significant shape variations between males and females, as well as young and adult wild boars based on morphometric analysis of the ramus mandibulae.

Endo et al. and Alberella et al. (2009) had demonstrated geographic and temporal variation in complete mandibles and teeth $\left(\mathrm{M}_{3}\right)$ Sus scrofa through classical morphometrics. However, sexual dimorphism and agerelated variation were not properly demonstrated through this method. Furthermore, Pedone et al. argued sexual dimorphism is not evident in juveniles. To the contrary, our results showed significant age- and sex-differences in ramus mandibulae in wild boars.

In spite of the obvious cranial sex-dimorphism among adult wild boars, there is a lack of formal morphometric descriptions about these differences. Among ungulates, body size dimorphism is higher in those species which have polygynous mating systems, with males being larger than females (Pérez-Barbería et al., 2002). This is usually related to the hypothesis of forage-selection and sexual segregation (Pérez-Barbería \& Gordon; Ruckstuhl \& Neuhaus, 2002). Wild boars are relatively large polygynous mammals (Fernández-Llario et al., 1999). However, male and female suids do not exhibit true spatial segregation, though most species are sexually dimorphic. Sus scrofa, for instance, shows marked sexual dimorphism between adult forms (Azorit \& Moro, 2010) with temporal segregation, however; they do not exhibit spatial sexsegregation (Spitz \& Janeau, 1995). McPherson \& Chenoweth (2012) pointed out that males may have exaggerated secondary sexual characteristics due to their relative lower investment effort in the reproductive process than that observed in mammalian females. Mammalian males could allocate more energy into secondary sex characteristics than females whose priority is the reproductive investment in gestation and lactation
(McPherson \& Chenoweth). On the other hand, even among ungulates with low sexual dimorphism (such as Tayassuidae), morphological and morphofunctional sexand age-variations are present (Sicuro et al., 2011). Tayassu and Pecari females display greater skull robustness in width of braincase and lambdoidal crest. Differences in the sexual maturation rates between males and females could lead to morphofunctional differences due to different energetic demands among sexes (Sicuro et al., 2011). Enlarged mandibles in female members of the Cervidae family, for instance, allow increased herbage intake to help meet the additional nutritional demands of gestation and lactation (Bartosiewicz, 1987; McPherson \& Chenoweth).

Most mammalian females reach puberty and physical maturity earlier than males (McPherson \& Chenoweth). Exceptions do occur, as in wild boars, where males and females reach puberty at similar ages. Wild boars become sexual mature at about 7-10 months of age, and females usually mate at around 18 months. In contrast, males only mate at around 2 to 3 years of age (Azorit \& Moro). Ovarian activity in adult females depends on autumn food resources and could be correlated with an increase of body weight (Aumaitre et al., 1984; Pépin \& Mauget, 1989). Due to higher energy demands in females during sexual maturity, pregnancy and suckling, one could suggest that distinct ecomorphological mechanisms could exist between male and female wild boars, which would justify the morphological differences observed on the ramus mandibulae of young wild boars.

Our results show the S. scrofa females' ramus mandibulae also exhibits a robust aspect. This hypertrophied area is related to attachment of all jaw adductor muscles. We hypothesize that this is associated with some ecomorphological mechanism related to the intake of different food items and energetic demands between sexes of adult wild boars. According to Azorit \& Moro, while the reproductive success of male wild boars after puberty relies on their capacity to compete with older males, the sexual maturation and reproductive activity of females are both directly related to their bodily development. The female's diet is determinant to their body development and, thus, indirectly related to their sexual maturation. These differences on the sexual maturation mechanisms between male and female wild boars might be reflected in the anatomical structure of their mandibles. This hypothesis, however, demands an empirical approach for its validation, once this information is virtually absent in the wild boar literature.

On the other hand, age differences in the ramus mandibulae could be associated with variation in jaw 
mechanics throughout the ontogenetic process. Myology studies have assessed the masticatory systems during ontogenetic development of Sus scrofa. Anapol \& Herring (2000) studied the ontogeny of histochemical fiber types and muscle function in the masseter of miniature Sus scrofa. They concluded that the proportion and array of these fibers change during ontogeny due to different masticatory systems related to feeding differences between age classes. The masseter muscle complex is attached to the angular process' outer face. Furthermore, Dardaillon (1989) pointed out the influences of the ontogeny on feeding choices of wild boars. Thus, agerelated differences found in the ramus mandibulae shape may indicate an overall osteo-muscular alteration during the ontogeny of the masticatory system, and possibly relates to the use of different food items throughout the development of an individual.

\section{ACKNOWLEGEMENTS}

We thank Dr. Mariana Loguercio and Dr. Andrea Cardini for their critics and suggestions, as well as, Dr. Eliete Bouskela and the staff of the BioVasc for all their support.

HOHL, L. S. L.; SICURO, F. L.; AZORIT, C.; CARRASCO, R. \& ROCHA-BARBOSA, O. Variaciones geométricas de la Ramus mandibulae en mandíbulas de Sus scrofa (Mammalia: Artiodactyla) según edad y sexo. Int. J. Morphol., 32(4):1282-1288, 2014.

RESUMEN: Se describen las variaciones morfológicas a nivel de la rama mandibular del jabali (Sus scrofa) en función del sexo y la edad. Se analizó material procedente de jabalíes juveniles ( $\mathrm{n}=27,15$ machos y 12 hembras) y adultos ( $\mathrm{n}=23,13$ machos y 10 hembras) a través de la morfometría geométrica (2-D) para valorar diferencias entre grupos. Se encontraron diferencias a nivel de la forma del ángulo mandibular entre edades y sexos, de manera que los individuos juveniles presentaron un ángulo más abultado y un proceso coronoides orientado hacia atrás, mientras que los adultos muestran una rama mandibular más estrecha y vertical, así como, un proceso coronoides orientado ortogonalmente. En las hembras la parte posterior de la mandíbula es más abultada y compacta que en los machos. Los cambios morfológicos entre juveniles y adultos están relacionados con los procesos ontogenéticos que afectan al complejo osteomuscular durante el crecimiento. Por otra parte, las variaciones morfológicas observadas en los adultos podrían tener relación con diferencias en la dieta entre ambos sexos.

PALABRAS CLAVE: Mandíbula; Ontogenia; Dimorfismo sexual; Jabalí.

\section{REFERENCES}

Albarella, U.; Dobney, K. \& Rowley-Conwy, P. Size and shape of the Eurasian wild boar (Sus scrofa), with a view to the reconstruction of its Holocene history. Environ. Archaeol., 14(2):103-36, 2009.

Anapol, F. \& Herring, S. W. Ontogeny of histochemical fiber types and muscle function in the masseter muscle of miniature swine. Am. J. Phys. Anthropol., 112(4):595-613, 2000.

Aumaitre, A.; Qudrd, J. P. \& Peiniau, J. Influence du milieu sur la reproduction hivernale et la prolificitd de la laie. In: Spitz, F. \& Pdpin, D. (Eds.). Toulose, Symposium International sur le Sanglier. Les Colloques de l'INRA 22, 1984. pp.69-78.

Azorit, C. \& Moro, J. Jabalí (Sus scrofa Linnaeus, 1758). In: Moreno, J. S. \& Sebastián, A. L. (Eds.). Ungulados silvestres de España: biología y tecnologías reproductivas para su conservación y aprovechamiento cinegético. Monografía INIA. Serie Medioambiental. $\mathrm{N}^{\circ} 2$. Madrid, Instituto Nacional de Investigación y Tecnología Agraria y Alimentaria, 2010. pp.21540.

Bartosiewicz, L. Sexual dimorphism in the cranial development of Scandinavian moose (Alces alces (L.) alces). Can. J. Zool., 65(3):747-50, 1987.
Bookstein, F. L. Landmark methods for forms without landmarks: morphometrics of group differences in outline shape. Med. Image Anal., 1(3):225-43, 1997.

Cucchi, T.; Hulme-Beaman, A.; Yuan, J. \& Dobney, K. Early Neolithic pig domestication at Jiahu, Henan Province, China: clues from molar shape analyses using geometric morphometric approaches. J. Archaeol. Sci., 38(1):11-22, 2011.

Dardaillon, M. Age-class influences on feeding choices of freeranging wild boars (Sus scrofa). Can. J. Zool., 67(11):2792-6, 1989.

Endo, H.; Maeda, S.; Yamagiwa, D.; Kurohmaru, M.; Hayashi, Y.; Hattori, S.; Kurosawa, Y. \& Tanaka, K. Geographical variation of mandible size and shape in the Ryukyu wild pig (Sus scrofa riukiuanus). J. Vet. Med. Sci., 60(1):57-61, 2002.

Fernández-Llario, P.; Carranza, J. \& Mateos-Quesada, P. Sex allocation in a polygynous mammal with large litters: the wild boar. Anim. Behav., 58(5):1079-84, 1999.

Fonseca, C. \& Correia, F. O Javali. Coleção Património Natural Transmontano. Mirandela, João Azevedo Editor, 2008. pp. 168. 
HOHL, L. S. L.; SICURO, F. L.; AZORIT, C.; CARRASCO, R. \& ROCHA-BARBOSA, O. Age and sex-related geometrical variation of Ramus mandibulae of Sus scrofa' (Mammalia: Artiodactyla) jaws. Int. J. Morphol., 32(4):1282-1288, 2014.

Genov, P.; Massei, G. \& Nikolov, H. Morphometrical analysis of two Mediterranean Wild boar populations. Ibex J. Mt. Ecol., 3:69-70, 1995.

Groves, C. P. \& Grubb, P. The sumargin Suiformes. In: Oliver, W. L. R. (Ed.). Pigs, peccaries, and hippos: status survey and conservation action plan. Gland, International Union for Conservation of Nature and Natural Resources, 1993. pp.1-4.

Gunz, P.; Mitteroeker, P. \& Bookstein, F. L. Semilandmarks in three dimensions. In: Slice, D. E. Modern Morphometrics in Physical Anthropology. Chicago, University of Chicago Press, 2005. pp.73-98.

McPherson, F. J. \& Chenoweth, P. J. Mammalian sexual dimorphism. Anim. Reprod. Sci., 131(3-4):109-22, 2012.

Moretti, M. Biometric data and growth rates of a mountain population of Wild boar (Sus scrofa L.), Ticino, Switzerland. Ibex J. Mt. Ecol., 3:56-9, 1995.

Pedone, P.; Mattioli, S. \& Mattioli, L. Body size and growth patterns in Wild boars of Tuscany, Central Italy. Ibex J. Mt. Ecol., 3:668,1995 .

Pépin, D. \& Mauget, R. The effect of planes of nutrition on growth and attainment of puberty in female wild boars raised in captivity. Anim. Reprod. Sci., 20(1):71-7, 1989.

Pérez-Barbería, F. J. \& Gordon, I. J. The functional relationship between feeding type and jaw and cranial morphology in ungulates. Oecologia, 118(2):157-65, 1999.

Pérez-Barbería, F. J.; Gordon, I. J. \& Pagel, M. The origins of sexual dimorphism in body size in ungulates. Evolution, 56(6):127685,2002 .

Rohlf, F. J. TpsDig, digitize landmarks and outlines, version 2.0. New York, Department of Ecology and Evolution, State University of New York at Stony Brook, 2004.

Ruckstuhl, K. E. \& Neuhaus, P. Sexual segregation in ungulates: a comparative test of three hypotheses. Biol. Rev. Camb. Philos. Soc., 77(1):77-96, 2002.

Sáez-Royuela, C.; Gomariz, R. P. \& Tellería, J. L. Age determination of european wild boar. Wildlife Soc. B., 17(3):326-9, 1989.

Sheets, H. D. MakeFan6 [Online]. 2003. Available in: http:// www3.canisius.edu/ sheets

Sicuro, F. L.; Neves, L. F. M. \& Oliveira, L. F. B. Sex- and agerelated morphofunctional differences in skulls of Tayassu pecari and Pecari tajacu (Artiodactyla: Tayassuidae). J. Mammal., 92(4):828-39, 2011.

Spitz, F. \& Janeau, G. Daily selection of habitat in wild boar (Sus scrofa). J. Zool., 237(3):423-34, 1995.
Standring, S. Gray's Anatomy: the anatomical basis of clinical practice. $40^{\text {th }}$ ed. New York, Churchill Livingstone, 2008.

Turnbull, W. D. Mammalian masticatory apparatus. Geol., 18(2):149-356, 1970.

Viscosi, V. \& Cardini, A. Leaf morphology, taxonomy and geometric morphometrics: a simplified protocol for beginners. PLoS One, 6(10):e25630, 2013.

Correspondence to:

Leandro dos Santos Lima Hohl, BSc.

Universidade do Estado do Rio de Janeiro - UERJ

LAZOVERTE - Laboratório de Zoologia de Vertebrados Tetrapoda

PHLC sl. 522a - Departamento de Zoologia, IBRAG

Rua São Francisco Xavier, 524 - Maracanã

CEP: 20550-013 Rio de Janeiro, RJ

BRAZIL

Email: leandrohohl@gmail.com

Received: 01-08-2014

Accepted: 29-09-2014 